\title{
ANALYTICAL AND EXPERIMENTAL STUDIES ON WEAR BEHAVIOUR OF CAST AND HEAT TREATED ALSI12CUMGNI AND ALZN6MGCU MATRIX COMPOSITES REINFORCED WITH CERAMIC PARTICLES, UNDER SLIDING CONDITIONS
}

\author{
Ileana NicoletaPopescu ${ }^{1}$, Ivona Camelia Petre ${ }^{2, *}$ and Veronica Despa ${ }^{3}$ \\ 1,2,3 Valahia University of Targoviste, 13 AleeaSinaia Street, Targoviste, Romania \\ E-mail: petreivonacamelia@yahoo.com
}

\begin{abstract}
The working conditions of the composite materials used to produce machine parts lead to different forms of wear. The fact that, for example, for a a kinematic coupling with sliding motion is often used a material with higher hardness (cast iron, steel) in combination with a material with a lower hardness (a composite material) there is the possibility of wear through abrasion and local plastic deformations. The paper proposes an analytical model for the determination of wear, depending on the angle of inclination of the roughness of the hard surface. The experimental wear investigations were made on cast iron disc (300HB hardness) at room temperature using a "pin on disc" machine, at and contact pressure and sliding speed. The composite consisted from cast and heat treated AlSi12CuMgNi and AlZn6MgCu matrix reinforced with Al2O3 and Graphite combined in different proportion, in the 0-5 volume percent range. The experimental results of the wear for the different materials are analyzed and compared to the analytical ones. The comparison of the experimental and the theoretical results confirms the veracity of the model and corresponds with many of the experimental results obtained in the specialized works.
\end{abstract}

Keywords: Wear Behaviour, Aluminium Matrix Composites, Ceramic Reinforcement.

\section{Introduction}

The wear process, consisted in material separation followed by the change in the initial condition of the friction surfaces, results in wear of the friction coupler. Due to the degradation of the surfaces in contact there is a change in the dimensions of the respective parts as well as in the operation of the friction coupler, which is not desirable.

From the tribological point of view, an optimal correlation should be found in the selection of the friction coupler materials, the surface treatment mode and the loading and exploitation conditions. Metallic matrix composites ( $\mathrm{Al}, \mathrm{Cu}, \mathrm{Fe}$, etc. matrix) reinforced with soft ceramic particles (Graphite, $\mathrm{MoS}_{2}$ etc.) have the objective to: (i) stabilize the developed friction coefficient during braking, particularly at high temperatures; (ii) decrease wear of disc and also (iii) increase grippe resistance [1-4]; (iv) exhibit a low friction coefficient (compared to composites reinforced with hard ceramic particles [5-8]) are mostly used in tribological applications without lubrication. We could say that this type of material is a balance of mechanical resistance with reduced friction and wear. Thanks to these benefits, these materials are often used in the construction of various kinematic couplers with sliding motion, because besides the benefits presented above they have a specific low density and environmental resistance. The tribological characteristics of the materials can be improved by adding both hard and ceramic reinforcement components ( $\mathrm{SiC}, \mathrm{TiC}, \mathrm{Al}_{2} \mathrm{O}_{3}$, $\mathrm{SiO}_{2}, \mathrm{ZrO}_{2}$, or Mullite) in combination with soft ones (Graphite, $\mathrm{MoS}_{2}$ ) [9-12], which recommends them as new solutions for the vehicle braking system. Used in combination with gray cast iron as a slidingengagement couple, they have good thermal conductivity (required for proper heat removal due to friction) [13-16]. By analyzing the tribological behavior of couplings "pin" (Al composites) on "disc" (cast iron), we follow the evolution of the wear intensity according to pressure, speed, mode of surface processing).

This paper proposes a theoretical model of wear characterization and comparison of the obtained results with the experimental ones.

\section{Analytical Model for Calculation of Wear Composite Material}

As it is known from the literature [10,11, 17-29] the appearance of a wear or other shape depends, in 
particular, on the ratio of the hardness of the surfaces in contact, the surface processing mode, the contact pressure between the conjugated surfaces, the exploitation conditions, etc. Abrasion wear is a form of wear present in most slip-resistant couplings with essentially different hardness but is also accompanied by other types of wear depending on the kinematic coupling specificity. Wear generally has the effect of reducing the size of the parts and is accompanied by the separation of the wear particles.

The experimental researches and the theoretical investigations carried out by Khruschov.[26, 27], Koplalinsky [28] , Huq, [29] have shown that the basic law of abrasive particles detachment is of the form:

$$
I_{u v} \approx \frac{U_{v}}{L_{f}}
$$

here: $\mathrm{I}_{\mathrm{uv}}$ is the volumetric wear intensity; $\mathrm{U}_{\mathrm{v}}$ is the volume of waste material; $\mathrm{L}_{\mathrm{f}}$ is the length of friction.

If the contact surface of the contacting kinematic coupler remains constant over the wear period $\left(A_{n}\right.$ nominal area) and the thickness of the worn layer is uniform then:

$$
I_{u v}=\frac{U_{v}}{L_{f}}=\frac{A_{n} \cdot d}{L_{f}}=A_{n} \cdot I_{u h}
$$

Where: $d$ is the depth of wear; $I_{u h}$ is the linear wear intensity.If the friction surfacesofthe coupling elements havedifferent hardnesses, micro-scraping processes may occur in the contact area.Under the same friction path and the same nominal contact pressures, the thickness of the coat depends on thesurfaces hardness. To formulate this hypothesis, many researchers [29-31], consider the Archard wear law, according to which the wear volume $U_{v}$ is directly proportional to the normal force $\left(F_{n}\right)$ and the friction length $\left(\mathrm{L}_{\mathrm{f}}\right)$ and inversely proportional to surface hardness $(\mathrm{H})$ :

$U_{v}=K \frac{F_{n} \cdot L_{f}}{H}$

Where: $\mathrm{K}$ is the proportionality factor.

The proportionality factor is considered as a wear ratio (Archard) and a material characteristic.

The values of this coefficient are always subunits, usually $10^{-3} \ldots 10^{-9}$ of the order of magnitude.

\section{Experimental Part}

\subsection{Selection of Materials}

Discontinuous particle reinforced Metal Matrix Composites (MMCs) are particularly attractive because in addition to their low cost of manufacture, they can be shaped by conventional metalworking processes [6-13, 33]. This has led to increased interest in the potential for large-scale use of particle reinforced MMCs in the automotive industry as materials for pistons, connecting rods, brake rotors, calipers and liners [34-36].

The wear behavior of $\mathrm{Al}_{2} \mathrm{O}_{3}$ particle reinforced MMCs has been extensively studied by various workers [5-8] and the tribological characteristics of $\mathrm{Al}-\mathrm{Si} / \mathrm{Graphite}$ for cylinder liners was studied in detail by B.P. Krishnan et. al. [34]. The wear resistance of particulate reinforced MMCs depends mainly on the particle size, particle volume fraction and matrix alloy properties [1-13]. Al-Si alloys are commonly used in the manufacture of automotive engine components such as cylinder blocks, pistons and piston insert rings. The principal reasons for the usage of $\mathrm{Al}-\mathrm{Si}$ alloys are their good castability, high corrosion resistance [35] and low density. The wear resistance of $\mathrm{Al}-\mathrm{Si}$ alloys is strongly dependent on the alloy composition, applied load and sliding speed $[4,34]$. The wear resistance of these alloys can be enhanced by the incorporation of a hard ceramic phase in the soft $\mathrm{Al}$ alloy matrix. On base of good physical and mechanical characteristics of hardening by thermal treatment of $\mathrm{AlZn}_{6} \mathrm{MgCu}$ alloys $[37,38]$ we choose thise alloys as matrix. Graphite (Gr), in the form of fibers or particulates, has long been recognized as a high-strength, low-density material [1-4]. Al/Gr particulate MMCs produced by solidification techniques represent a class of inexpensive tailor-made materials for a variety of engineering applications such as automotive components, bushes, and bearings. Their uses are being explored in view of their superior technological properties such as the low coefficient of friction, low wear rate, high damping capacity and good machinability [34-36].

$\mathrm{Al}_{2} \mathrm{O}_{3}$ particles are the most commonly used reinforcements in MMCs and the addition of these reinforcements to aluminium alloys has been the subject of a considerable amount of research works[7]. Preparation and casting of material composites was presented in details in a previous work [9]. The heats treated of composites [9] consisted in: (i) Solution treatment of $480 \pm 5^{\circ} \mathrm{C} / 60$ min and quenced in water and artificial ageing at $140 \pm 5^{\circ} \mathrm{C} / 12$ hours, air quenched, for $\mathrm{AlZn}_{6} \mathrm{MgCu} /\left(\mathrm{Gr}, \mathrm{Al}_{2} \mathrm{O}_{3}\right)$ materials; (ii) Solution treatment of $520 \pm 5^{\circ} \mathrm{C} / 6$ hours and quenced in water and artificial ageing at $170 \pm 5^{\circ} \mathrm{C} / 14$ hours, air quenched, for $\mathrm{AlSi}_{12} \mathrm{CuMgNi} /\left(\mathrm{Gr}, \mathrm{Al}_{2} \mathrm{O}_{3}\right)$ materials.

\subsection{Mechnical Testing}

The mechanical test was Brinell hardness according with Romanian standards STAS201/2 for $\mathrm{AlSi}_{12} \mathrm{CuMgNi}$ matrix composites and STAS7608/88 for $\mathrm{AlZn6MgCu}$. 


\subsection{Tribological Experiments}

We determined the average wear rate for all types of composites and unreinforced matrix in cast state.

The disc was polished before each tribological test. The tribological tests were performed on the pin-on-disc type wear machine, under following condition: contact pressure (applied load) $3.5 \cdot 10^{-1} \mathrm{MPa}$ and $7.5 \times 10^{-1} \mathrm{MPa}$, relative sliding speed of $3.8 \mathrm{~m} / \mathrm{s}$ at constant temperature, only for heat treated materials.

All tests were run under dry sliding conditions.

The dimensions of all samples was $10 \times 10 \times 10 \mathrm{~mm}$.

The height $(\mathrm{mm})$ of the worn layer was measured after sliding the pin-on-disc. The obtained results were the average of three- four measurements and the time of wear test was kept constant in all cases at 30 min.

\subsection{Mechnical Characteristics}

The Brinell hardness was measured for the two types of composites (Al-Si based, and Al-Zn based materials). Fig. (a) shows the hardness of AlSi12CuMgNi matrix composite reinforced with particles of graphite and $\mathrm{Al}_{2} \mathrm{O}_{3}$, in varying proportions, for both untreated and treated composite materials. Figure 1 (b) shows the hardness of the $\mathrm{AlZn}_{6} \mathrm{MgCu}$ matrix composite under the same experimental conditions.

It is obvious that for composite materials with a higher graphite percentage the hardness decreases.

After heat treatment of aluminium based composites, age hardening appears leading to increasing of hardness. These aspects are confirmed by experimental results when for the materials to which treatments have been applied the hardness is higher than the untreated ones. In the case of materials reinforced with $\mathrm{Al}_{2} \mathrm{O}_{3}$, we observe that the higher the percentage of $\mathrm{Al}_{2} \mathrm{O}_{3}$, leading to the higher of hardness. Our results confirmed that the materials with hard ceramic particles $\left(\mathrm{Al}_{2} \mathrm{O}_{3}\right)$ in composition are harder than those with soft ceramic (Gr) particles in composition.

\subsection{Tribological Results}

Wear (loss in height/ the depth of the lost layer $[\mathrm{mm} / \mathrm{h}]$ ) ns for heat treated AlSi12CuMgNi (see Fig. 2) and $\mathrm{AlZn} 6 \mathrm{MgCu}$ (see Fig.3) respectively reinforced with graphite or/and $\mathrm{Al}_{2} \mathrm{O}_{3}$ particles for 0.35MPa and 0.75 MPa (see Fig. and Fig.).

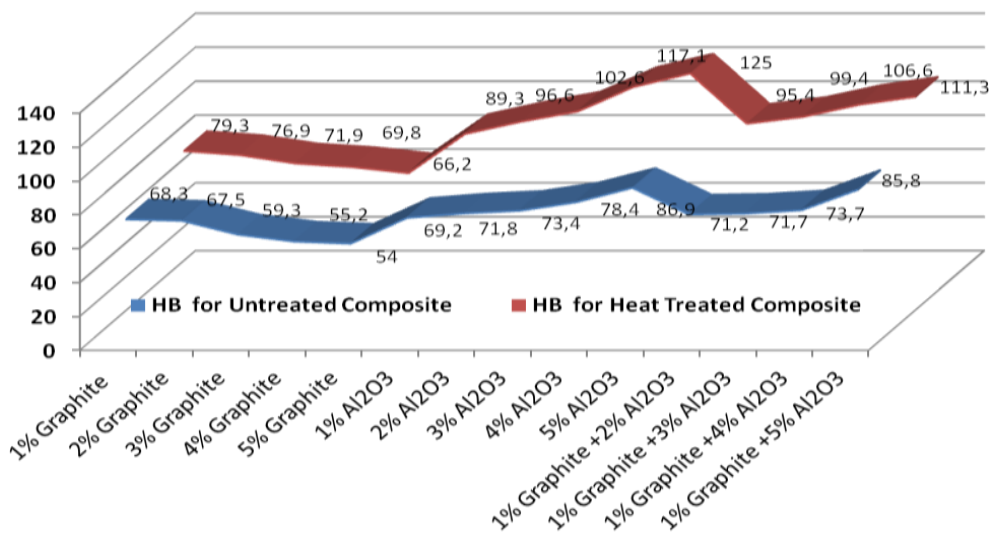

(a)

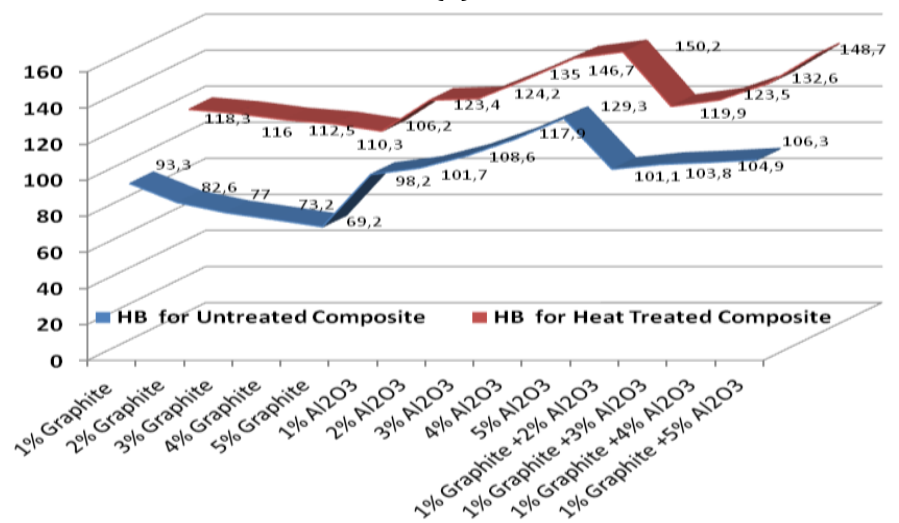

(b)

Figure 1: The average values of Brinell Hardness (HB) for (a) AlSi12CuMgNi and (b) for AlZn6 6 MgCu matrix composites in untreated and heat treated conditions. 
3.6 Comparison of Calculated Volume of Wear, Based on the Theoretical Model, with the Results Obtained Experimentally

For some known working conditions (hardness, loading, friction length, etc.) the theoretical volume of wear can be determined. Fig. 4 shows the theoretical evolution of the volume of waste material (for $\mathrm{AlZn} 6 \mathrm{MgCu} / \mathrm{Gr}$ ) for a friction length $L f=7 \cdot 10^{7}$ $m m$, a load of $F_{n}=0.35 \mathrm{MPa}$, hardness $H=70 \ldots 95 \mathrm{HB}$ and various proportional value $(K)$ values.

It is worth noting that the theoretical volume of wear decreases with increasing the material hardness. If replacements are made then the volumetric wear intensity:

$\mathrm{I}_{\mathrm{uv}}=\mathrm{K} \frac{\mathrm{F}_{\mathrm{n}}}{\mathrm{H}}$

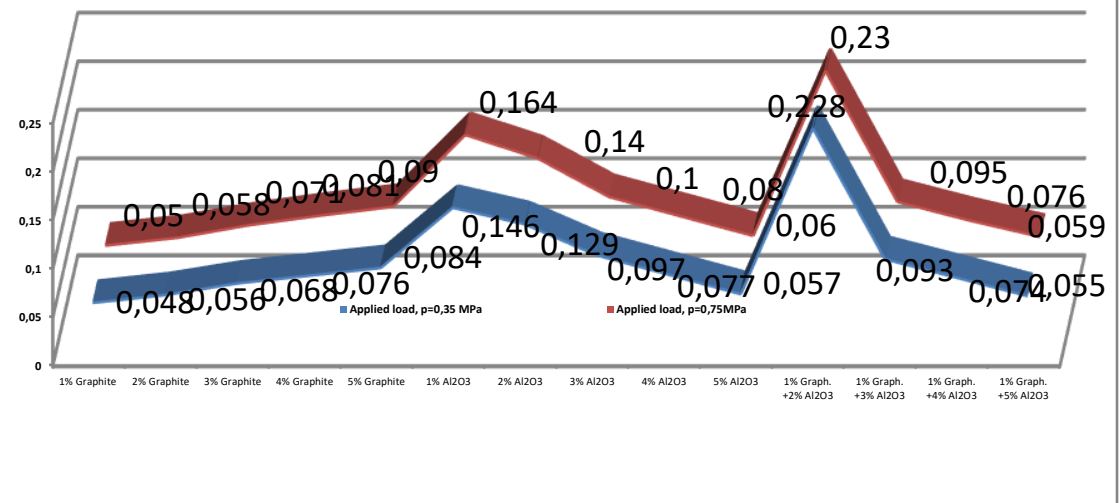

Figure 2: The average values of determined wear $[\mathrm{mm} / \mathrm{h}]$ ) for AlSi12CuMgNi based composite depending on different proportion (\%vol.) of the Graphite or/ and Al203 reinforcement particles.

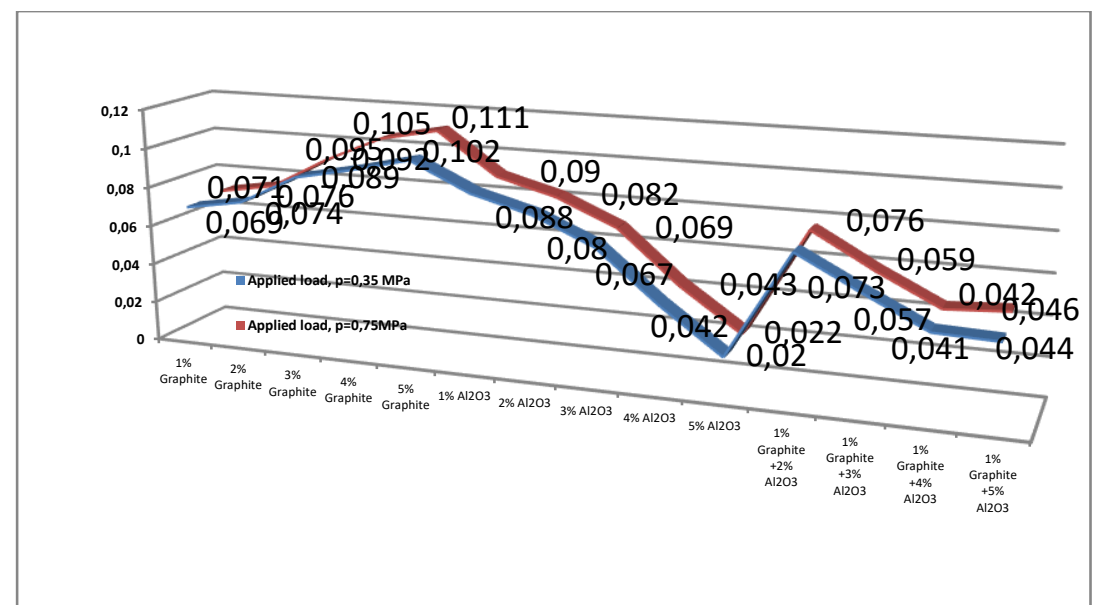

Figure 3: The average values of determined wear $[\mathrm{mm} / \mathrm{h}]$ ) for AlZn6MgCu based composite depending on different proportion (\%vol.)of the Graphite or/ and Al203 reinforcement particles

As mentioned, the processing of the surfaces in contact has a decisive influence on the evolution of the wear intensity. It is considered a rigid surface (1) at which the angle of attack of the cone (inclination of the asperities) is $\alpha$, which moves at a constant speed on a deformable plastic plane (2), characterized by the shear resistance $\tau_{\mathrm{f}}$.

In this case, the ratio between the volume of deformed and removed material ( $\left.U_{v}\right)$ and the friction length $\left(\mathrm{L}_{\mathrm{f}}\right)$ under normal load $\left(\mathrm{F}_{\mathrm{n}}\right)[28,31$, $39,40,41]$ is:

$\mathrm{K}_{\mathrm{A}}=\frac{\mathrm{U}_{\mathrm{v}}}{\mathrm{L}_{\mathrm{f}} \cdot \mathrm{F}_{\mathrm{n}}}=\frac{1}{2 \cdot \tau_{\mathrm{f}}} \frac{(\sin \alpha)^{2}+0,5 \cdot \sin 2 \alpha}{1+\sin \alpha}$

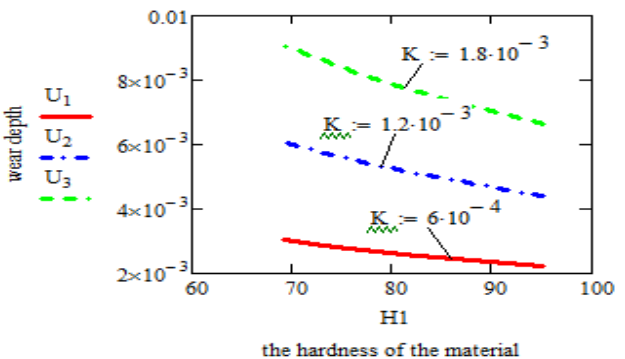

Figure 4: Theoretical evolution of used material volume for AlZn6MgCu/Gr for known conditions 
Accepting Tabor's hypothesis that the shear resistance $\left({ }^{\tau_{f}}\right)$ of a material is dependent on the hardness of the material $(\mathrm{H})$ :

$$
\tau_{\mathrm{f}}=\frac{\mathrm{H}}{3 \sqrt{3}}
$$

The Archard wear coefficient $(\mathrm{K})$ can be determined.

For these reasons, the wear volumetric intensity will be:

$$
\mathrm{I}_{\mathrm{uv}}=\frac{2 \cdot \operatorname{tg} \alpha}{\pi \cdot \mathrm{H}} \cdot \mathrm{F}_{\mathrm{n}}
$$

Figure 5 shows the evolution of the wear intensity for one of the analyzed materials ( $\mathrm{AlZn}_{6} \mathrm{MgCu}$ reinforced with $\mathrm{Al}_{2} \mathrm{O}_{3}$ ), the loading function $(p=0.35 \mathrm{MPa})$ and the angle of inclination of the rigid cone. From the graph analysis in Figure 5 it is worth noting that for a certain inclination of the conical penetrator the wear intensity increases slightly, and then there is a rapid increase of the wear. This indicates that for rigid cone angles lower than $55^{\circ}-60^{\circ}$ a moderate wear is occurring, after that, for larger angles $60^{\circ}-65^{\circ}$, a severe wear occurs. The explanation of this is due to the response behavior of the material with lower hardness under the action of the conical penetrator.

At small angles, the material deforms in the form of a wave (without detachment of particles) by microploughing and at higher angles then the $60^{\circ}$ micro-cracking of the microcutting material takes place (see Fig. 6).

The transition from waveform deflection to micro-deflection occurs when the tilt angle of the rigid cone exceeds a critical value $\left(\alpha_{c r}\right)$, the value which depends on the characteristics of the studied material [18]. This theoretical evolution (depending on the processing of the surface of the materials) corresponds to many of the experimental results obtained in the specialized works [18, 42-44].

Fig. 7 shows the evolution of wear intensity calculated for AlZn6MgCu with 2\% Gr and 2\% Al203 respectively, for $p=0.75 \mathrm{MPa}$ ).

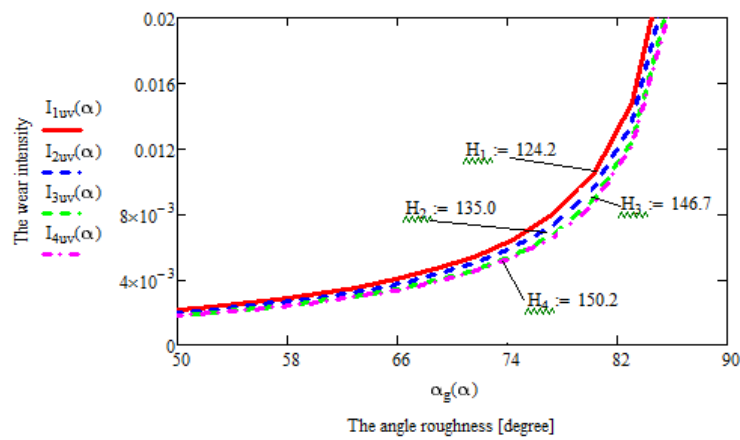

Figure 5: .Evolution of wear intensity with hardness of AlZn6MgCu /Al2O3 composite (Ii.uv( $\alpha$ ), depending of loading and tilt angle of rigid cone.

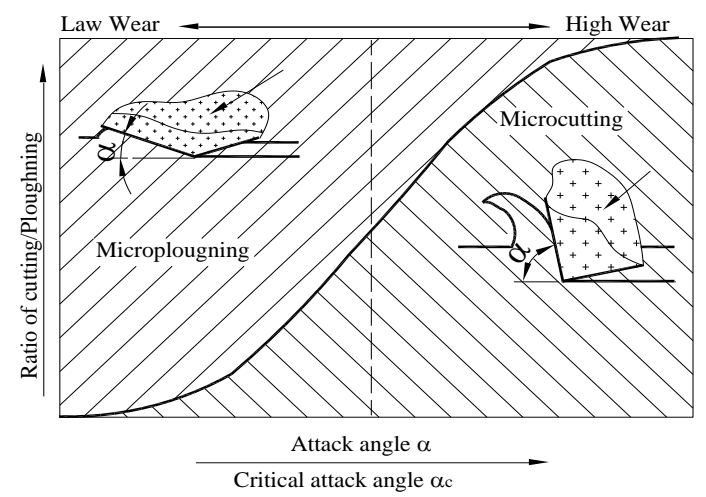

Figure 6: Ratio of microcutting to microploughing as a function of the ratio of the attack angle to the critical attack angle.

Fig. 8 shows the evolution of wear depth for AlSi12CuMgNi reinforced with graphite or Al2O3 particles for the two working pressures $0.35 \mathrm{MPa}$ and $0.75 \mathrm{MPa}$. It is note-worthy that for AlSi $12 \mathrm{CuMgNi}$ the depth of the wear layer increases with increasing graphite content and decreases as the content of Al203 increases.

Fig. 9 present the theoretical and experimental results of the volume of waste material, obtained for AlZn6MgCu reinforced with graphite particles (Fig. 9a) and Al203 (Fig. 9b). It is noted that for low values of reinforced materials percentage $(0 \%-2 \%)$, the results are not essentially different.



Figure 7: Evolution of wear intensity depending on the angle of attack cone and reinforced material

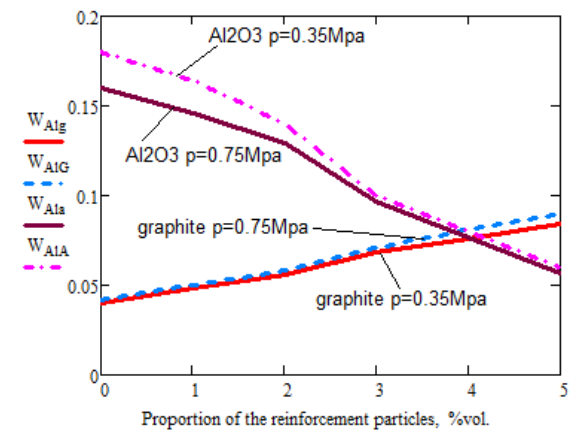

Figure 8: Evolution of wear layer with pressure and reinforcement (\% vol), for AlSi12CuMgNi with graphite or $\mathrm{Al} 2 \mathrm{O3}$ 




(a)

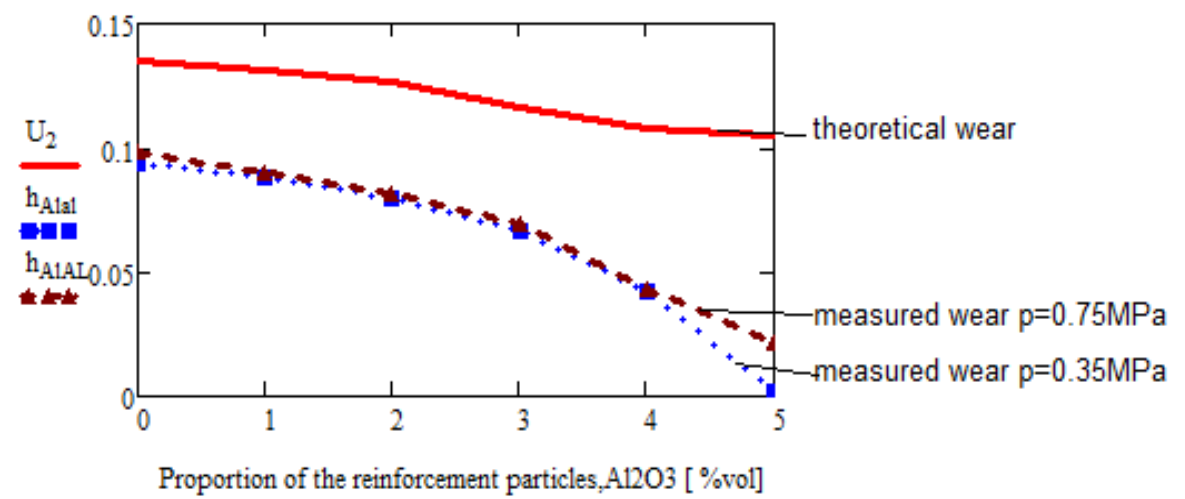

(b)

Figure 9: Evolution of volume of material used with pressure and proportion of

(a) Graphite (\% vol), respectively; (b) Al2O3 (\% vol), for AlZn6MgCu based composite.

\section{Conclusions}

Knowing the height (depth) of the used material, the dimensions of the samples and the length of the friction, under experimental conditions, it is possible to determine the volume of used material that will be compared to that obtained theoretically. In the present paper we also found the following: (a) under the experimental conditions it was not possible to highlight the way of processing the material due to the small dimensions of samples. In this case, we can't compare the obtained values; (b) the theoretical model has highlighted the fact that the way of processing the friction surfaces (materialized by the angle of inclination of the asperities) influences the wear. For tilting angle values a mild wear occurs, above this value wear significantly increases; (c) the increase of the wear intensity according to the angle of machining of the asperities is explained by the fact that at the angles there is the deformation of the material without detachment of microploughing particles, and at higher angles there occurs micro forming deformation of the material, which makes that wear will grow rapidly; (d) in the theoretical model it was emphasized that with the increase of the graphite content the wear increases, which is also confirmed by the experiments; (e) comparing the theoretical and experimental results, it has been found that samples made of embedded graphite materials wear out more than those with the same processing and loading conditions (pressure, speed); (f) comparing the theoretical model with the experimental results it was confirmed that wear decreases with increasing material hardness; (g) in the experiments we can see the increase of the depth of the used layer with the load; (h) under experimental conditions also, for $\mathrm{AlSi}_{12} \mathrm{CuMgNi}$ and $\mathrm{AlZn}_{6} \mathrm{MgCu}$ analyzes, the depth of the wear layer increases with increasing graphite content and decreases as the content of $\mathrm{Al}_{2} \mathrm{O}_{3}$ increases.

\section{References}

[1] Anderson, A. E.: Friction and wear of automotive brakes, in: ASM handbook, vol.7. Powder Metallurgy, ASM International, USA, 569-577 (1984).

[2] Chan, D., Stachowiak, G.W.: Review of automotive brake friction materials, Proceedings of the Institution of Mechanical Engineers, Part D: Journal of Automobile Engineering 218 953-966 (2004). 
[3] Popescu, I.N., Ghiţă, C., Bratu V., Palacios Navarro, G.:Tribologicalbehaviour and statistical experimental design of sintered iron-copper based composites, Applied Surface Science 285 (PartA), 72-85 (2013).

[4] Furlan, K.P., da Costa Gonçalves, P., Consoni,D.R., et al.: Metallurgical Aspects of Self-lubricating Composites Containing Graphite and MoS2, Journal of Materials Engineering and Performance 26 (3), 1135-1145 (2017).

[5] Petre, I.C., Popescu, I.N.: The Phenomenological Analysis of the Nature of the Friction, from Theoretical and Experimental Point of View of AlAl203-Graphite Composite /Cast Iron „Pin On Disc" Sliding System, International Journal of Mechatronics and Applied Mechanics, Issue 2, 40-47 (2017).

[6] Popescu, I.N., Vidu, R., Bratu, V., Olei, A.B., Ungureanu, D.N., Anghelina, F.V.: Effects of Silicon Carbide Proportion and Artificial Aging Parameters on Microstructure and Hardness of $\mathrm{Al}-\mathrm{Cu} / \mathrm{SiCp}$ Composites, Solid State Phenomena 216, 122-127 (2015).

[7] Yang, L.J,:The transient and steady wear coefficients of A6061 aluminium alloy reinforced with alumina particles, Compos. Sci. Technol. 63 (3-4) 575-583 (2003).

[8] Popescu, I.N., Zamfir, S, Bojin, D, et. al.:Physical and Quantitative Microstructural Analysis of Sintered Al-Cu/SiCpComposites,Materials Science Forum 672, 251-254 (2011).

[9] Popescu, I.N., Bratu, V., Filip, V., Catangiu, A. , Ungureanu, D.N., Anghelina, F.V.Tribological and mechanical behavior of cast $\mathrm{Al}$ particulate composites and hybrid Al matrix composites, Scientific Bulletin of ValahiaUniv.Materials and Mech. 4,109-116 (2009).

[10] Kaushik, N. Ch., Rao, R.N.:Influence of Applied Load on Abrasive Wear Depth of Hybrid $\mathrm{Gr} / \mathrm{SiC} / \mathrm{Al}-\mathrm{Mg}-\mathrm{Si}$ Composites in a Two-Body Condition, J. Tribol 139(6) 061601, (2017).

[11] Sima, G., Mangra, M., Gîngu, O., Criveanu, M.C., Olei, B.A.: Influence of the Reinforcing Elements on the Wear Behavior of $\mathrm{Al} /(\mathrm{SiC}+\mathrm{Graphite})$ Composites Elaborated by Spark Plasma Sintering Technology, Materials Science Forum 672, 241-244 (2011).

[12] Popescu, I.N., Zamfir, S., Anghelina, F.V., Rusanescu, C.O.: Fabrication through $\mathrm{P} / \mathrm{M}$ of ecological aluminum based composite materials. Part 1-Characterization and densification of mixture powders, Proceedings of the 2 nd Int. Conference on MEQAPS Constantza, 200-205 (2010).

[13] Tandon, K.N. Feng, Z.C.: Wear behaviour of SiC part reinforced Al composites against steel balls under dry and lubricated condition, Trybology Letter 6, 113-122 (1999).
[14] Petre, I., Stoian, E.V., Enescu, M.C.: Determining the Heat Regime in the Working of a Coupling with Sliding Motion, Scientific Bulletin of Valahia University-Materials and Mechanics 14 (11) 33-38 (2016).

[15] Rusănescu, C.O., Rusănescu, M., Anghelina, F.V.: Variation of mechanical properties with temperature for an ecomaterial, Optoelectronics and advanced materials - Rapid communications 11-12, 947-951 (2013).

[16] Tudor, A.Frecareaşiuzareamaterialelor, Editura Bren Bucuresti pp 158-179 (2002).

[17] Tudor, A., Vlase, M .: Uzareamaterialelor, Editura Bren București pp 232-246 (2010).

[18] Coronado, J. J., Abrasion resitence of materials, InTechJanezaTrdinePublisher, Marcin, A.(eds.) pp 167-184 (2012).

[19] Ghita, C., Pop, N. and Popescu, I.N.: Existence result of an effective stress for an isotropic viscoplastic composite, Computational Materials Science, 64, 52-56 (2012).

[20] Olei, B.A, Ştefan, I., Popescu, N.: The influence of the sintering temperature on the wear testing for some steels samples obtained by powder metallurgy, Solid State Phenomena 216, 216-221 (2014).

[21] Petre, I., Popa, C., Dumitru, D., Manescu, C.: Analytical model of calculus for influence the translation guide wear over the machining accuracy on the machine tool, Fiability\& Durability/FiabilitatesiDurabilitate 2(6) 17-22 (2010).

[22] Petre, I., Poinescu, A.A., Catangiu, A., Mihai, S.: Studies regarding the reaction method to wear braking mechanism, The Scientific Bulletin of Valahia University Materials and Mechanics 15, 37-42 (2017).

[23] Bratu, V., Popescu, I.N., Stoian, E.V., Ungureanu, D.N., Rusănescu, C.O., Toma, L.G., Voicu, A,C.: Casting and homogenization of AlCu3.3Mg1.5Mn Al alloys for aircraft industry, Advanced Materials Research 1128, 44-50 (2015).

[24] Popescu, I.N., Zamfir, S., Anghelina, V.F., Rusănescu C.O.: Processing by $\mathrm{P} / \mathrm{M}$ route and characterization of new ecological Aluminum Matrix Composites (AMC), Internationa Journal of Mechanics 4 (3) 43-52 (2010).

[25] Rusănescu, C.O., Rusănescu, M., Ioedănescu, T., Anghelina, F.V.:Mathematicalrelation ships between alloying elements and technological deformability indexes, Journal of optoelectronisc and advanced materials 15 (7-8),718-723 (2013).

[26] Khruschov, M. M.:Resistence of metals to wear by abrasion as related to hardness, London, Inst. Mech. Engineers (1957).

[27] Khruschov, M.M.: Principles of abrasive wear, Wear 28, 69-88 (1974). 
[28] Kopalinsky, E.M., Oxley, P.L: Explaining the mechanics of metallic sliding friction and wear in terms of slipline field models of asperity deformation,Wear190(2)145-154 (1995).

[29] Huq, M. Z., Celis,J.-P.:Expressing wear rate in sliding contacts based on dissipated energy Wear252, 375-383 (2002).

[30] Kato, K.: Classification of Wear Mechanisms/Models Journal of Engineering Tribology 349-355 (2002).

[31] Hutchings, I., Shipway, P.:Tribology: Friction and Wear of Engineering Materials, Published by Elsevier pp 174-217 (2017).

[32] Zmitrowicz,A.:Wear patterns and laws of wear, Journal of theoretical and applied mechanics 44, 219-2532006

[33] Popescu, I.N., Bratu, V., Ionescu, M, Chivu, M, Enescu, M.C., Poinescu, A.A.: Preparation and characterization of cast aluminium/graphite composites and hybrid aluminium composites, Scientific Bulletin of Valahia University 4, 104108 (2009).

[34] Krishnan, B.P., Raman, N, Narayanaswamy, K. et.al.: Performance of An Al-Si Graphite Particle Composite Piston in a Diesel Engineering, Wear 60, 205-215 (1980).

[35] Popescu, I.N., Enescu, M.C., Bratu, V., Zamfir, R.I., Stoian, E.V.:Development, Microstructure and Corrosion Resistence of Al-Mg-(Si) binary and ternary system samples in $5.3 \% \mathrm{NaCl}$ solution for applications with environmental impact, Advanced Materials Research, Trans Tech Publications, Switzerland 1114, 239-244 (2015).
[36] Prasad, S.V. and Asthana, R.: Aluminum Metal Matrix Composites for Automotive Applications: Tribological Considerations, Tribol. Lett. 17(3) 445-453 (2004).

[37] Enescu, M.C., Popescu, I.N., Zamfir, R., Molagic, A., Bratu, V,::Influence of heat treatment on microstructure and corrosion behavior of $7 \mathrm{xxx}$ $\mathrm{Al}$ alloys, Proceedings of the 2nd International Conference on MEQAPS, 212-216 (2010).

[38] Ibrahim, I.A., Mohamed, F.A., Lavernia,E.J.: Particulate Reinforced Metal Matrix Composites, A Review, J. Mater. Sci., 26(5) 1137-1156 (1991).

[39] Challen, J.M., Oxley, P.L.B :An explanation of different regimes of friction and wear using asperity deformation models, Wear 53, 229-243 (1979).

[40] Hiroshi, M.: Surface deformation and formation of original element of wear particles in sliding friction Wear 215(1-2) 10-17 (1998).

[41] Xie, Z., Williams, J.A.: The prediction of friction and wear when a soft surface slides against a harder rough surface Wear 196, 21-34 (1996).

[42] Black, A.J., Kopalinsky, E.M.,,Oxley, P.L.B. An investigation of the interaction of model asperities of similar hardness Wear 153, 245-261 (1992).

[43] Koji, K., Koshi, A.: Wear Mechanisms (Chapter7), New Direction in Tribology London, http://home.ufam.edu.br/berti/nanomateriais/8 403_PDF_CH07.pdf (1997).

[44] Torrance, A.A.: The influence of surface deformation on mechanical wear, Wear 200, 4554 (1996). 